\title{
NAOJ's activities on Astronomy for Development: Aiding Astronomy Education in Developing Nations
}

\author{
K. Sekiguchi and F. Yoshida \\ Office of International Relations National Astronomical Observatory of Japan \\ E-mail: kaz.sekiguchi@nao.ac.jp
}

\begin{abstract}
We summarize NAOJ's efforts to promote astronomy in developing nations. The Office of International Relations, collaborations with the Office of Public Outreach at NAOJ and with the East Asia Core Observatories Association (EACOA), has engaged children, students and educators about astronomy development in the Asia-Pacific region. In particular, we introduce "You are Galileo!" project, which is a very well received astronomy education program for children. We also report on a continuing effort by the Japanese Government in support of astronomy programs in the developing nations.
\end{abstract}

\section{1. "You are Galileo!" project}

"You are Galileo!" project, which is a continuing program from the IYA2009 to attract children's interest in astronomy by looking through a small telescope they built themselves, has been supported by the Japanese National Committee for UNESCO. This extremely successful project has brought astronomy within the grasp of children in developing regions and helped children to pursue careers in science and engineering. Two recent campaigns were held in Indonesia and in Mongolia in 2011.

In Indonesia, we had five workshops, at Jakarta, Yogyakarta, Mataram, Tomohon and Palembang, for teachers of the elementary and the secondary schools. A total of 230 teachers attended. In Mongolia, six workshops for the teachers and children were conducted. A total of 289 teachers and children attended the workshops and over 600 people showed up for the star parties. For more information, please refer to the following URL: http://kimigali.jp/index-e.html

\section{Japans Official Development Assistance (ODA) programme for astronomy}

Since 1982, the Japanese Government has donated 27 units of astronomical equipment to 22 nations. 7 of the items donated were professional-grade reflecting telescopes with scientific instruments, such as CCD cameras and/or spectrographs, which can be used for photometric and spectroscopic observations. In addition to these, 20 planetarium systems have been installed at universities and space-education museums. Kitamura M. et al. gave detailed information about this program. Follow up assistance programs, supported by Japan International Cooperation Agency (JICA) and some public observatories in Japan, to give technical and observation training, have been conducted.

\section{References}

Kitamura, M., et al., 2008, Third UN/ESA/NASA Workshop on the International Heliophysical Year 2007 and Basic Space Science, Earth Moon and Planets, p49. 